\title{
The Future of Historical European Martial Arts Studies.
}

\section{A discussion}

\author{
Daniel Jaquet, \\ Centre d'Études Supérieures de la Renaissance (Tours).

$$
\text { daniel.jaquet@unige.ch }
$$

\begin{abstract}
The two panels of the conference were concluded by a round-table aiming at discussing the future of HEMA studies, by crossing the views of the speakers on three levels: personal involvement, major contribution needed for the field, strategies to make it happen. This article will focus on (1) reviewing the most important matters discussed and to balance them with the latest published desiderata for further research, (2) situating them in the latest developments in, on the one hand, martial arts studies, and on the other, Practice as Research (PaR) in other fields of research, and finally (3) comparing them with the developments of a similar fields of study over the last 60 years, notably dance studies.
\end{abstract}

Keywords - Historical European Martial Arts studies, Dance studies, Musicology, communities of practitioners.

The two panels ended with a discussion round with the speakers featured in this volume, and moderated by the author. ${ }^{1}$ The formalised objective was to discuss the future of HEMA studies, by crossing the views of the speakers on three levels: personal involvement, major contribution needed for the field, strategies to make it happen. It was followed by an open discussion with the attendance, providing insights from different fields of studies or disciplines, as well as comments and reactions to the matters at hand. Instead of attempting to render this discussion in a written form, I shall focus here on (1) reviewing the most important matters according to my opinion and to balance them with the latest published desiderata for further research, ${ }^{2}$ (2) situating them in the latest developments in, on the one hand, martial arts studies, and on the other, Practice as Research $(\mathrm{PaR})$ in other fields of research, and finally (3) comparing them with the developments of a similar field of study over the last 60 years, notably dance studies.

\footnotetext{
1 A videotape of the discussion is available on the Youtube channel of the Journal (uploaded September 01, 2016). One of the speakers is not included in this volume (James Hester).

2 Jaquet et al., "Conclusion”, p. 594-602 [desiderata for further research, p. 597-600].
} 


\section{CONTEXTUALISING THE MARTIAL CULTURES OF FIGHTING: MICRO AND MACRO SCALE RESEARCH}

Martial arts are embodied knowledge ${ }^{3}$ framed into a specific society and its cultural settings. While interpreting the traces of technical instruction on how to fight is of interest to the practitioner, it is less so for the scholar seeking to understand it in its context. Approaching this level of contextualisation implies going through the interdisciplinary or antidisciplinary - methods of cultural studies, with the key concern of examining the forces within and through which socially organised people conduct and participate in the construction of their everyday lives. ${ }^{4}$

HEMA studies should therefore stress the historical and cultural context of their object of research. There are many ways to do this, but the benefits of one out of several was particularly discussed: the micro scale history (C. F. Sorenson). At the same time, it is worth putting such approach in series and comparing them one to another. Moreover, as a second or third step, it is also relevant to tackle the macro scale, with a comparative research between larger areas in time and space, even such as East and West (S. Wetzler).

Of course there are many tensions between macro and micro scale research, especially when it comes to define the object of research and the sources. One amongst many dangerous shortcuts is to generalise the fighting techniques as being an application of violence related to warfare, as if violence was severed from other areas of socio-cultural life. The danger lies then in considering the various traces of fighting techniques connected only to training and practices in "warfare-related" situations. There is a wide range of other contexts where a fighting technique can be applied and leave traces for the researcher to study, including self-defense, physical exercise and leisure, ritualised combat forms, and so on. ${ }^{5}$ This issue relates to a main concern of the larger field of martial arts studies, aiming at understanding the ways in which martial arts are institutionalised within a specific society. ${ }^{6}$ This is one way to conceptualise how martial arts are practiced and where the line between recognised and forbidden practice is drawn. With a historical perspective, the processes of defining the borders of this - sometimes fictionalised dichotomy would then produce source material to be studied.

\footnotetext{
${ }^{3}$ Farrer and Whalen-Bridge (eds.), Martial Arts as Embodied Knowledge.

${ }^{4}$ Cultural studies as a field stemmed from British scholars in the 1950-1970, and are nowadays diffracted into a variety of national and international developments. See Hall, "Cultural studies and its theoretical legacies". For a definition of martial culture of fighting as a concept, see Burkart in this volume.

5 See the desiderata: "Fighting arts (martial arts?) in context" and "Sociology of the Fight Masters" in Jaquet et al., "Conclusion”, pp. 599-600.

${ }^{6}$ Bowman, Martial Arts Studies, chap. 1.
} 


\section{THE FIGHT BOOKS AS PRINCIPAL SOURCE?}

When it comes to apply these theoretical roadmaps to actual research on fighting cultures, the researcher has to adapt his methods to his defined object of research and his sources. A common denominator for most of the participants of the panels are Fight Books. The tendency to consider these technical sources as one specific genre leads to several issues, since the corpus is highly heterogeneous, comprising a range of different documents: the personal notes of a master or a student, copies of authoritative texts sometimes with potential shifts of both media (text and image) and content over time, to potentially "didactic" manuals, or at least some form of instructional literature (J. Deacon). This relates to a desiderata for further research (inception, authorial project and reception), which intends to establish a typology, or at least forms of categorisation within the corpus. $^{7}$ This mandatory step is sadly often overlooked and leads to a lack of critical views on the main source material for its potential representativeness for actual historical fighting practices (E. Burkart).

The researcher pursuing a micro-scale approach is then drawn to highlight his main source material with other type of document (administrative, normative, narrative, etc.). The danger is however to make connections that are disputable, or worse to use a comparative approach between sources, which cannot be compared to one another. Such mistakes are commonly found in the production of independent researchers from the community of practitioners, but also to be found in scholarly publication sadly relying on widespread misconceptions (most of them to be traced to late $19^{\text {th }}$-early $20^{\text {th }}$ c.).

Another feature of research on fighting practices is the use of other type of sources to highlight issues stemming from the study of Fight Books. Material culture (arms, armour, objects, costume), as well as representation of fighting techniques in art (monumental sculpture or painting, iconographical depiction in documents ${ }^{8}$ ) are used as data for an empirical approach. The downside is that it is often very difficult to establish a documented connection between a specific representation or an object with a specific Fight Book. The door is then opened to disputable overgeneralisation and would turn the empirical approach as invalid, since either the collection of evidence was gathered in a disputable manner, or the question cannot be answered with the collected evidences. This issue concerns as well the relevance for scholarly research of modern-day interpretation of fighting techniques out of Fight Books (experiencing versus experimenting). ${ }^{9}$

\footnotetext{
7 Jaquet et al., “Conclusion”, p. 598. See also Verelst et al., "Introduction”.

8 See the desiderata: "Iconology of the Fight Books", in Jaquet et al., "Conclusion", p 598.

9 See the desiderata: "Towards a scientific approach to gesture", in ibid., p. 599.
} 


\section{THE NEED FOR RESEARCH TOOLS AND RESOURCES}

The lack of authoritative (or recognised) milestone publication ${ }^{10}$ leads the researchers involved in HEMA studies to use different terms and concepts to refer to the same issue or object. This was the case during the discussion held at the IMC, adding confusion even within the small circle of experts themselves, but with more potential damage for the broader academic audience outside of the field. Beyond issues of terminology, it is the lack of scholarly sound research tools and resources which is highly problematic. This is the same conclusion that was reached in the recent German conference held in Chemnitz last February. ${ }^{11}$ In order to turn the HEMA studies from emergent to established field of study, several major research work need to be published, including:

Edition of sources: Actually, there is a lot of material available online on exchange or wiki-like platforms. Most of these efforts stems from the communities of practitioners and were permitted through the politic of digitalisation of manuscripts and prints by the patrimonial or research institutions. Sadly, most of these works do not meet scientific expectations and are not published on stable url, which implies that they cannot be used for scholarly research (even if there is relevant material published online, it is difficult to separate the wheat from the chaff). Research initiative should be able to rely on trusted resources, either a collection of editions published digitally (with a stable url, maybe even encoded with TEI) or a dedicated series by a publishing house. ${ }^{12}$

Research tools (encyclopaedia, catalogue, bibliography): There are many bibliographies available for history of fencing, sadly none are exhaustive or up to date. Recent catalogues of sources or specialised bibliographies are available, each of those with their limits and restriction to a dedicated part of the corpus. ${ }^{13}$ Encyclopaedia articles for authors or works are also scattered and mainly in need to be updated. ${ }^{14}$ Other research tools such as database of fencing masters, authors or works would also be welcomed.

10 See the short review of historiography in Verelst et al., "Introduction", p. 16-17.

11 "Kunst dye dich zyret: Fechten als Mittel persönlicher und institutioneller Repräsentation", organisation Thore Wilkens, Technische Universität Chemnitz, 18-20.02.2015.

12 See the desiderata: "Scientific edition of the sources", in Jaquet et al., "Conclusion", p 597.

13 For example, Leng et al., Fecht- und Ringbücher or Valle Ortiz, Nueva bibliografia de la antigua Escgrima.

14 For German sources, the recent edition of the vol. 7 of the Deutsches Literatur-Lexicon (Aschnitz, Das wissensvermittelnde Schrifttum im 15. Jahrhundert) contains updated articles for most of the German authors, with contribution from Matthias-Johannes Bauer, Rainer Welle and Thore Wilkens. These contributions update nicely the Verfasser-Lexicon with the contribution of Hans-Peter Hils. 


\section{PRACTICE AS RESEARCH: THE COMMUNITIES OF PRACTITIONERS AND THE SCHOLARS}

There is a relatively long history in the epistemology of theoretical versus practical aspects of research. Recent developments include the notions of "situated knowing", a wellknown concept in social science, but transferred in anthropology and cognitive science (with recent interest in history-related disciplines), and "practice as research" (PaR), stemming from theatre and performance studies. ${ }^{15}$ From a theoretical point of view, knowing cannot be separated from doing, therefore all knowledge is situated in actions related to a socio-cultural context. Embodied knowledge such as martial arts, studied in a historical or cultural perspective, should therefore include a practical aspect in the research, or at least be informed by practical experts (in other words, practitioners).

There are, however, palpable tension between scholars and independent researchers from the practitioners' community o. ${ }^{16}$ Most of these tensions could be defused if both parties would at least attempt to understand the objectives, means and best practices from both worlds. Nevertheless, some issues will be difficult to ease. From a practitioner point of view, the scepticism and critical view of the scholar towards the source material and its interpretation by practitioners remains most of the time obscure. From a scholarly point of view, the endeavours in interpreting fighting techniques from Fight Books and the hours spent in the gym remain elusive and distant, since bodily knowledge and experience cannot be easily converted to words.

Nevertheless, as argued by Spatz, Farrer and others, practice can be considered as research and interpretation of fighting techniques from Fight Books are relevant for HEMA studies, at least from my point of view. There are other field of research where the same issues were faced and relevant results were and are currently produced. Musicology for instance has a history of over 100 years of mixing practitioners research endeavours and expertise with academic research, even if there are still debates within the field for the relevance or irrelevance of reconstruction (see Burkart). I would like to focus on another, younger, field of research: the dance studies.

\section{DANCE STUDIES DEVELOPMENT FRAMEWORK AS A MODEL?}

In 1950s, scholars interested in history of dance attempted to make sense of a technical literature inscribing, describing or codifying embodied knowledge. They faced the same issue (difficulties in interpreting the source material) and some of them looked for expertise from the practitioners' milieu. The first learned society was founded in New

\footnotetext{
15 See the review in Spatz, What a body can do, pp. 217-253 (PaR, see pp. 225-234)

16 See Jaquet, "The researcher status in Historical European Martial Arts communities of practitioners", and Jaquet and Sorenson, "Historical European Martial Arts - a crossroad...".
} 
York in 1964 (Committee on Research in Dance) ${ }^{17}$ and, besides organising congresses, they issued the first academic journal in 1968: Dance Research Journal. In Europe, learned societies were also formed, in United Kingdom in 1978 (Society of Dance History Scholars), in Germany in 1986 (Gesellschaft für Tanzforschung), etc. At that point, the field of research was global and established. The first chairs for Dance studies or dedicated laboratories in academic institutions burgeoned in the 1980s, to become common features in most countries in Europe in the late 1990s.

As for HEMA studies, dance studies had also previous smaller developments prior to the constitution of the first learned society and the publication of the academic journal. However, those two steps turned the field of research from emergent to established in a period of ca. 20 years. I believe that the emergent field of research that we name HEMA studies is about to become an established one in the next 10 years, if we manage to reach a critical mass of (academic) investigators on an international level. We do not yet have a learned society, but strong networks are already existing and we have managed to publish the first international academic journal dedicated to our field for four years now (vol. 1 of Acta Periodica Duellatorum in 2013).

With the international growth of communities of practitioners, now organised in national federations or national bodies, some of those united under the banner of an international federation (International Federation for Historical European Martial Arts, constituted in 2013), the practice of HEMA reaches out of its inner circles. The tensions between scholars and independent researchers are natural, but can be overlooked if research (a term in need to be defined for all parties) is paramount to practice. Most of the national federations or national bodies do their best to promote research. It is now time for the constitution of a proper academic learned society. The Society for Historical European Martial Arts Studies is already in the making and will hopefully play a critical role in establishing our field of study in the next decade.

\section{BIBLIOGRAPHY}

\section{VI.1. Secondary sources}

Aschnitz, Wolfgang, ed., Das wissensvermittelnde Schrifttum im 15. Jahrbundert, Deutsches Literatur Lexicon, Band 7 (Berlin, Boston: De Gruyter, 2015).

Bowman, Paul, Martial Arts Studies (London; New York: Rowman Littlefield, 2015).

Farrer, Douglas S., and John Whalen-Bridge, eds., Martial Arts as Embodied Knowledge: Asian Traditions in a Transnational World (New York: SUNY Press, 2011).

17 They changed their name to Congress on Research in Dance in 1977 and are still in activity. 
Hall, Stuart, 'Cultural Studies and Its Theoritical Legacies', in Stuart Hall: Critical Dialogues in Cultural Studies, ed. by Kuan-Hsing Chen and David Morley (London: Routledge, 1996), pp. 261-74.

Jaquet, Daniel, 'The Researcher Status in Historical European MArtial Arts Communities of Practitioners', in Martial Arts Studies in Germany - Defining and Crossing Disciplinary Boundaries, ed. by Martin Joh Meyer (Hamburg: Czwalina, 2016), pp. 3950 .

Jaquet, Daniel, and Claus Frederik Sorenson, 'Historical European Martial Art - a Crossroad between Academic Research, Martial Heritage Re-Creation and Martial Sport Practices.', Acta Periodica Duellatorum, 3 (2015), 5-35.

Leng, Rainer, Hella Frühmorgen-Voss, Norbert H. Ott, Ulrike Bodemann, Peter Schmidt, and Christine Stöllinger-Löser, Fecht-Und Ringbücher, Katalog Der Deutschsprachigen Illustrierten Handschriften Des Mittelalters, 38. Band 4/2, Lfg. 1/2., (München: Bayerische Akademie der Wissenschaften, 2008).

Valle Ortiz, Manuel, Nueva Bibliografia de La Antigua Escgrima Y Destreza de Las Armas (Santiago de Compostela: AGEA, 2012).

Jaquet, Daniel, in collab. with Karin Verelst, and Timothy Dawson, 'Conclusion', in Late Medieval and Early Modern Fight Books: Transmission and Tradition of Martial Arts in Europe (14th-17th Centuries), ed. by eadem (Leiden ; Boston: Brill, 2016), pp. 594-602.

Verelst, Karin, in collab. with Daniel Jaquet, and Timothy Dawson, 'Conclusion', in Late Medieval and Early Modern Fight Books: Transmission and Tradition of Martial Arts in Europe (14th-17th Centuries), ed. by eadem (Leiden ; Boston: Brill, 2016), pp. 7-30.

Spatz, Ben, What a Body Can Do: Technique as Knowledge, Practice as Research (London and New York: Routledge, 2015). 